\title{
PENGARUH CITRA DESTINASI WISATA DAN PENGALAMAN BERWISATA TERHADAP INTENSI MENGUNJUNGI KEMBALI PADA WISATAWAN OBYEK WISATA PEMANDIAN AIR PANAS GUNUNG TORONG KABUPATEN PANDEGLANG
}

\author{
Sabila Noerhanifati ${ }^{1}$, Dientje Griandini ${ }^{2}$, Terrylina Arvinta Monoarfa ${ }^{3}$ \\ Fakultas Ekonomi, Universitas Negeri Jakarta \\ Jl. R.Mangun Muka Raya, Rawamangun, Kota Jakarta Timur \\ Email Korespondensi : sabilanoerhanifati_pb16s1@mahasiswa.unj.ac.id
}

\begin{abstract}
ABSTRAK
Tujuan dari penelitian ini adalah untuk menguji pengaruh citra destinasi wisata dan pengalaman berwisata yang tak terlupakan terhadap intensi mengunjungi kembali pada wisatawan Obyek Wisata Pemandian Air Panas Gunung Torong. Metode yang digunakan dalam penelitian ini adalah metode survei. Data yang digunakan dalam penelitian ini merupakan data kuantitatif dengan analisis data menggunakan path analysis dengan SPSS versi 24. Populasi dalam penelitian ini adalah seluruh wisatawan Obyek Wisata Pemandian Air Panas Gunung Torong. Pengambilan sampel pada penelitian ini menggunakan metode Purposive Sampling. Sampel yang berhasil dijangkau dalam penelitian ini berjumlah 150 wisatawan Obyek Wisata Pemandian Air Panas Gunung Torong. Dalam uji koefisien determinasi variable keseluruhan dapat diketahui bahwa nilai Rsquare adalah 0,874. Hasil yang didapat dari penelitian ini adalah: (1) Terdapat pengaruh positif dan signifikan citra destinasi wisata terhadap intensi mengunjungi kembali. (2) Terdapat pengaruh positif dan signifikan keterikatan citra destinasi wisata terhadap pengalaman berwisata yang tak terlupakan. (3) Terdapat pengaruh positif dan signifikan pengalaman berwisata yang tak terlupakan terhadap intensi mengunjungi kembali. (4) Terdapat pengaruh positif dan signifikan citra destinasi wisata terhadap intensi mengunjungi kembali melalui pengalaman berwisata yang tak terlupakan.
\end{abstract}

Kata Kunci: Intensi Mengunjungi Kembali, Citra Destinasi Wisata, Pengalaman Berwisata Yang Tak Terlupakan

\begin{abstract}
The purpose of this study was to examine the effect of destination image and memorable tourism experiences towards revisit intention on tourist in Gunung Torong Hot Springs Park Pandeglang. The method used in this research is a survey method. The data used in this study are quantitative data with data analysis using path analysis with SPSS version 24. The population in this study were all tourists of Gunung Torong Hot Springs Park Pandeglang. Sampling in this study using purposive sample method. The sample that was successfully achieved in this study, 150 tourists of Gunung Torong Hot Springs Park Pandeglang. In the test for the coefficient of determination of the total variable, it can be seen that the Rsquare value is 0.874 . The results obtained from this study are: (1) There is a positive and significant effect of the image of a tourist destination on return visits. (2) there is a positive and significant influence on the attachment of the image of a tourist destination to an unforgettable travel experience. (3) the existence of a positive and significant impact of an unforgettable travel experience on return visits. (4) the existence of a positive and significant influence on the image of tourist destinations on return visits through unforgettable travel experiences.
\end{abstract}

Keyword: Revisit Intention, Destination Image, Memorable Tourism Experiences 


\section{PENDAHULUAN}

Dari sekian banyaknya kekayaan yang dimiliki oleh Indonesia, potensi terbesar bagi Indonesia yakni di sektor pariwisata, yakni dilihat dari sumber daya, ragam budaya, ragam kuliner maupun latar belakang sejarah pun mampu menjadi nilai jual bagi sektor pariwisata Indonesia. Sehingga, Indonesia mempunyai potensi untuk menjadi negara wisata yang digemari oleh wisatawan asing. Berikut data kunjungan wisatawan mancanegara dapat dilihat pada gambar berikut.

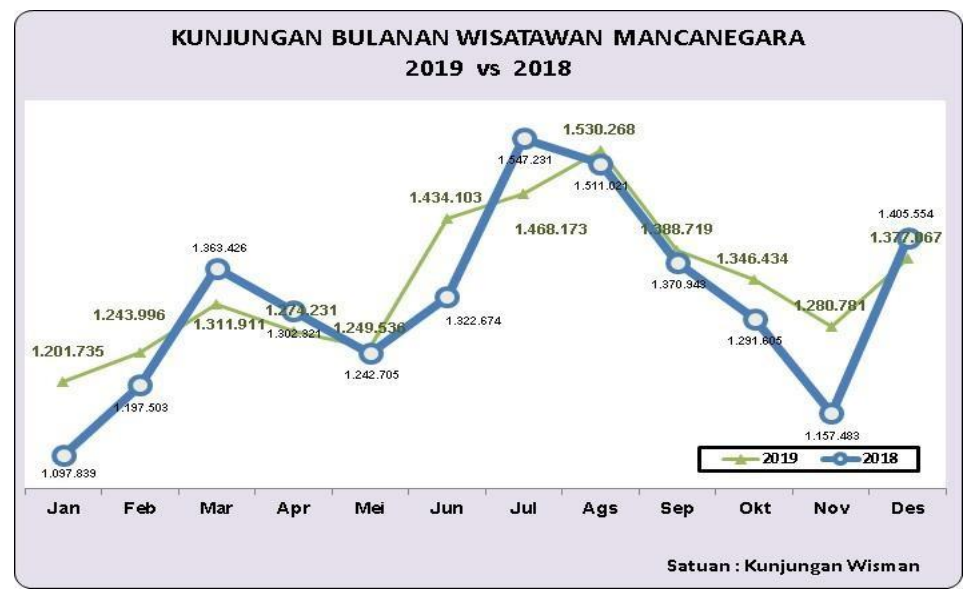

Gambar 1. Data Jumlah Kunjungan Wisman ke Indonesia Sumber : Kementrian Pariwisata, RI (2020)

Berdasarkan data dari Kementrian Pariwisata Republik Indonesia (2020), diketahui bahwa pada tahun 2018 hingga tahun 2019, jumlah kunjungan wisatawan mancanegara yang berkunjung ke Indonesia mengalami kenaikan dan penurunan. Dilihat dari kunjungan wisatawan mancanegara ke Indonesia melalui seluruh pintu masuk pada bulan Desember 2019 berjumlah 1.377.067 kunjungan, atau mengalami penurunan sebesar 2,03\% dibandingkan bulan Desember 2018 yang berjumlah 1.405.554 kunjungan.

Dengan demikian, tentunya mendorong Indonesia dalam bidang perekonomia Indonesia. Mengutip dari laman website Sindonews.com (2017), sektor pariwisata diproyeksikan mampu menyumbang produk domestik bruto untuk devisa negara, dengan adanya 20 juta kunjungan wisatwan mancanegara maupun 275 juta perjalanan wisatawan nusantara pada tahun 2019. Berdasarkan data tersebut, Pemerintah percaya bahwa sektor pariwisata diyakini mampu menciptakan pusat pertumbuhan ekonomi yang lebih baik.

Menurut Yoeti (2008:20), dilihat dari sudut pandang ekonomi makro, sektor pariwisata memberikan dampak positif bagi industri di suatu negara, diantaranya: meningkatkan kesempatan tenaga kerja, meningkatkan pendapatan sekaligus pemerataan pendapatan masyarakat, meningkatkan pendapatan nasional, maupun mendorong peningkatan investasi pada industri pariwisata serta sektor ekonomi lainnya.

Mengutip pada laman website Kementrian Pariwisata (2019), yang mengatakan bahwa sektor pariwisata diproyeksikan akan menjadi inti dari ekonomi suatu negara dan penyumbang devisa terbesar di Indonesia untuk lima tahun kedepan.

Dikutip dari laman website Wikipedia.com, Kabupaten Pandeglang merupakan salah satu Kabupaten Pandeglang yang berada di Provinsi Banten, yang terletak diantara $06^{\circ} 21^{\circ} 00-07^{\circ} 10^{\circ} 00^{\prime \prime}$ LS dan $105^{\circ} 48^{\circ} 00^{\prime \prime}-106^{\circ} 11^{\circ} 00$ BT dengan luas Wilayah $2.746,91$ $\mathrm{km}^{2}$. Selain itu, Kabupaten Pandeglang terkenal akan kawasan pariwisata. Karena 
memiliki banyak destinasi wisata yang beraneka ragam yakni, baik wisata alam maupun wisata budaya. Salah satunya, Obyek Wisata Pemandian Air Panas Gunung Torong. Merupakan salah satu wisata alam air panas yang terletak di Desa Sukamanah Kecamatan Kaduhejo, Kabupaten Pandeglang, Provinsi Banten. Pemandian Air Panas Gunung Torong sendiri mulai berdiri sejak tahun 2007. Air panas yang terdapat di pemandian air panas tersebut berasal dari Gunung Karang yang mengandung belerang, hal inilah yang menjadi ciri khas dari Obyek Wisata Pemandian Air Panas Gunung Torong. Berikut ini data kunjungan wisatawan Pemandian Air Panas Gunung Torong Tahun 2017-2019 dapat dilihat pada tabel berikut ini:

Tabel 1. Jumlah Kunjungan Wisatawan Obyek Wisata Pemandian Air Panas Gunung Torong

\begin{tabular}{|c|c|c|c|}
\hline \multicolumn{4}{|c|}{ Wisatawan } \\
\hline Bulan & $\begin{array}{l}\text { ahun } \\
2017\end{array}$ & $\begin{array}{l}\text { 'ahun } \\
2018\end{array}$ & $\begin{array}{l}\text { 'ahun } \\
2019\end{array}$ \\
\hline Januari & 19.098 & 15.772 & 20.994 \\
\hline Februari & 7.364 & 8.491 & 9.515 \\
\hline Maret & 8.617 & 9.253 & 11.242 \\
\hline April & 10.059 & 9.642 & 14.879 \\
\hline Mei & 9.204 & 10.914 & 4.089 \\
\hline Juni & 7.808 & 9.720 & 34.707 \\
\hline Juli & 15.785 & 21.016 & 16.064 \\
\hline Agustus & 10.771 & 10.224 & 15.587 \\
\hline September & 8.910 & 6.834 & 9.854 \\
\hline Oktober & 8.406 & 8.978 & 9.629 \\
\hline November & 8.594 & 9.029 & 10.091 \\
\hline Desember & 14.607 & 19.299 & 11.092 \\
\hline Jumlah & 129.223 & 139.172 & 167.743 \\
\hline
\end{tabular}

Berdasarkan data dari pengelola Obyek Wisata Pemandian Air Panas Gunung Torong, terlihat jumlah wisatawan yang datang pada tahun 2017 hingga tahun 2019 mengalami kenaikan. Sehingga, masalah inilah yang akan dijadikan objek penelitian dengan mengambil beberapa faktor lainnya sebagai variabel penelitian. Berdasarkan uraian tersebut, Pemandian Air Panas Gunung Torong seharusnya menaruh perhatian terhadap faktor-faktor yang mempengaruhi revisit intention. Perubahan jumlah kunjungan wisatawan Obyek Wisata Pemandian Air Panas Gunung Torong disebabkan oleh beberapa faktor, diantaranya yaitu citra destinasi wisata Obyek Wisata Pemandian Air Panas Gunung Torong.

Faktor pertama, yang mempengaruhi revisit intention adalah citra destinasi (destination image). Citra destinasi tempat wisata akan memberikan kepercayaan dan pendapat wisatawan untuk melakukan kunjungan kembali. Mengenai suatu destinasi, dan apa yang dirasakan wisatawan selama berwisata di tempat tujuan. Berikut beberapa alasan 
wisatawan memilih untuk berkunjung ke Obyek Wisata Pemandian Air Panas Gunung Torong dari sudut pandang citra destinasi wisata, diantaranya:

Tabel 2 Hasil Survei Awal Variabel Citra Destinasi Wisata (Destination Image)

\begin{tabular}{llc}
\hline Pernyataan & $\begin{array}{l}\text { Presentase } \\
\text { Jawaban }\end{array}$ \\
\hline Untuk terapi kesehatan & $41,7 \%$ \\
\hline Terdapat wahana permainan & $16,7 \%$ \\
\hline Harga tiket masuk terjangkau & $5,6 \%$ \\
\hline
\end{tabular}

Sumber: Data diolah oleh peneliti

Berdasarkan hasil survei awal yang dilakukan oleh peneliti melalui Google Form pada wisatawan Obyek Pemandian Air Panas Gunung Torong, wisatawan hanya boleh memilih satu jawaban dari pernyataan "apa yang menjadi alasan Anda menyukai Obyek Wisata Pemandian Air Panas Gunung Torong?”. Sebanyak 72 wisatawan menjawab, 41,7\% atau 31 wisatawan memilih untuk terapi kesehatan.

Pernyataan tersebut didukung penelitian yang dilakukan oleh Wibowo, et al. (2016), hasil penelitian tersebut menyimpulkan bahwa citra destinasi (destination image) berpengaruh signifikan terhadap minat mengunjungi kembali (revisit intention) dan kepuasan pengunjung (tourist satisfaction) berpengaruh signifikan terhadap minat mengunjungi kembali (revisit intention) pada Setu Babakan Kampung Budaya Betawi.

Kemudian, faktor kedua yang mempengaruhi intensi mengunjungi kembali (revisit intention) adalah pengalaman berwisata yang tak terlupakan (memorable tourism experiences). Pengalaman berwisata yang tak terlupakan dapat dirasakan wisatawan setelah mengunjungi suatu destinasi wisata pilihan mereka, apabila destinasi wisata yang dikunjungi dapat memberikan kesan. Berikut tanggapan wisatawan terhadap pengalaman yang dirasakan setelah berkunjung Obyek Wisata Pemandian Air Panas Gunung Torong, diantaranya:

Tabel 3 Hasil Survei Awal Variabel Pengalaman Berwisata (Memorable Tourism Experiences)

\begin{tabular}{lc}
\hline \multicolumn{1}{c}{ Pernyataan } & Presentase Jawaban \\
\hline Suasana tempat wisata yang menyenangkan & $31,9 \%$ \\
\hline $\begin{array}{l}\text { Tempat wisata strategis, akses jalan mudah } \\
\text { dijangkau }\end{array}$ & $4,1 \%$ \\
\hline mber: Data diolah oleh peneliti &
\end{tabular}

Berdasarkan survei awal yang dilakukan peneliti melalui Google Form pada wisatawan Obyek Pemandian Air Panas Gunung Torong, sebanyak 72 wisatawan menjawab pada pengalaman berwisata yang tak terlupakan, sebanyak 31,9\% atau 24 wisatawan memilih suasana tempat wisata yang menyenangkan. Hal tersebut didukung oleh penelitian terdahulu, berdasarkan penelitian yang dilakukan oleh Zhang, et al. (2018), pada penelitian tersebut dijelaskan bahwa Secara simultan atau bersama-sama citra negara (country image), citra destinasi (destination image) dan pengalaman berwisata yang tak terlupakan (memorable tourism experiences) memiliki pengaruh yang 
positif dan signifikan terhadap niat mengunjungi (revisit intention) kembali ke destinasi wisata.

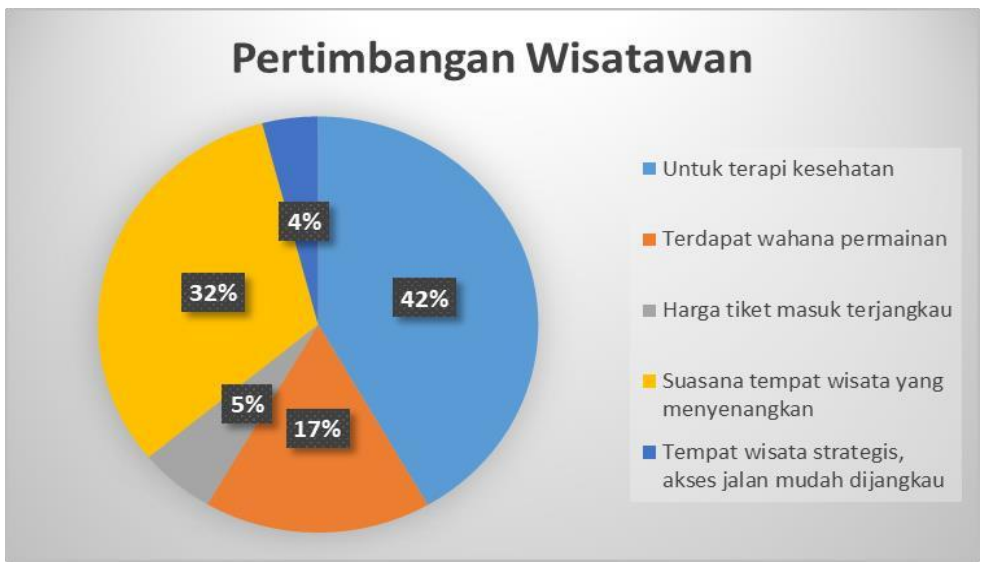

Gambar 2. Grafik Pertimbangan Wisatawan Memilih Obyek Wisata Pemandian Air Panas Gunung Torong

Pada gambar 2, berdasarkan hasil survei secara keseluruhan pada 72 responden wisatawan, bahwa sebesar $41,7 \%$ dari $100 \%$ pertimbangan wisatawan memilih berkunjung ke Obyek Wisata Pemandian Air Panas Gunung Torong yaitu untuk terapi kesehatan. Karena ciri khas dari Obyek Wisata Pemandian Air Panas Gunung Torong adalah air panas alami yang berkhasiat menyembuhkan beragam penyakit.

Berdasarkan latar belakang yang sudah diuraikan, maka dapat diidentifikasikan beberapa faktor yang mempengaruhi intensi mengunjungi kembali, diantaranya citra destinasi wisata (destination image) dan pengalaman berwisata yang tak terlupakan (memorable tourism experiences).

Berdasarkan kompleksnya permasalahan yang telah diuraikan, maka peneliti tertarik untuk melakukan penelitian mengenai "Pengaruh Citra Destinasi Wisata (Destination Image) dan Pengalaman Berwisata (Memorable Tourism Experiences) terhadap Intensi Mengunjungi Kembali (Revisit Intention) pada Wisatawan Obyek Wisata Pemandian Air Panas Gunung Torong Kabupaten Pandeglang”.

\section{Intensi Mengunjungi Kembali}

Menurut Wang et al., (2015:55) mengatakan revisit intention merupakan kemungkinan bagi wisatawan untuk mengunjungi kembali tempat wisata dan perilaku ini dianggap sebagai bentuk ungkapan kesetiaan. Menurut Wibowo et al., (2016:141) minat mengunjungi kembali merupakan bentuk perilaku dari pengalaman kunjungan sebelumnya terhadap kualitas jasa layanan destinasi di negara yang sama. Sedangkan, menurut Hyunjin (2013:112), minat mengunjungi kembali didefinisikan sebagai faktor penting untuk terus menciptakan keuntungan perusahaan atau kinerja dalam perspektif jangka panjang.

Dapat disimpulkan bahwa intensi mengunjungi kembali merupakan perilaku wisatawan untuk mengunjungi kembali tempat wisata yang akan dikunjungi di kemudian hari, bahwa niat mengunjungi kembali merupakan faktor penting dalam objek penelitian mengenai wisatawan. Dalam hal, kemungkinan wisatawan mengunjungi kembali suatu 
destinasi wisata.

Menurut Pratminingsih et al., (2014:19), konsep dari niat mengunjungi kembali berasal dari niat perilaku. Niat perilaku adalah niat untuk perencanaan dalam melakukan perilaku tertentu. Menurut Stylos et al., (2016:42), berpendapat bahwa revisit intention sebagai kesiapan dan kesediaan seseorang untuk membuat kunjungan ulang pada tujuan wisata yang sama.

Dari beberapa teori di atas, maka dapat disimpulkan bahwa niat mengunjungi kembali adalah niat perilaku pengunjung dalam perencanaan liburan yang direncanakan. Dan kemungkinan seseorang, untuk melakukan kunjungan berulang pada tujuan wisata setelah wisatawan memilih berkunjung.

Lin dan Chung-Hsien (2014:12) mengemukakan bahwa ada 2 bagian segmentasi dalam revisit intention, yaitu:

1) Intention to Revisit (keinginan untuk kembali berkunjung) yaitu, wisatawan mengunjungi kembali dan kemungkinan menjadi tujuan liburan berikutnya;

2) Intention to Recommend (keinginan untuk merekomendasikan kepada orang lain) yaitu, merekomendasikan kepada teman/saudara dan memberitahukan mengenai halhal positif.

Intensi mengunjungi kembali dapat diukur dalam dua dimensi. Dimensi pertama adalah keinginan untuk kembali berkunjung, dan dimensi kedua adalah keinginan untuk merekomendasikan kepada orang lain.

\section{Citra Destinasi Wisata}

Menurut Coban (2012:223), gambaran atau image sebuah destinasi adalah persepsi yang terbentuk menurut berbagai kabar yang diterima oleh pengunjung. Sedangkan, menurut Stylos et al., (2016:6) destination image merupakan serangkaian kesan, ide, harapan, dan pemikiran emosional yang dimiliki oleh seseorang dari tujuan yang telah ditentukan. Menurut Wibowo et al., (2016:140) mendefinisikan bahwa destination image adalah keputusan suatu perjalanan berdasarkan pemikiran individu berupa informasi, perasaan dan persepsi sebagai keseluruhan pemikiran tujuan dari pengalaman yang didasarkan taraf kepuasan pengunjung terhadap destinasi yang dikunjungi.

Dapat disimpulkan bahwa destination image merupakan persepsi dan pemikiran emosional yang dimiliki wisatawan dari suatu destinasi wisata.

Zhang, Xu, Leung dan Cai (2016:6) mendefinisikan citra tujuan wisata sebagai image citra produk wisata yang terkait dengan pusat tempat-tempat wisata dan fasilitas pariwisata, yang secara pribadi memenuhi kebutuhan wisatwan yang berkunjung. Menurut Hsu, Cai dan Li (2010:282), citra tempat merupakan faktor krusial berdasarkan kunjungan destinasi menjadi citra yang baik dari tujuan untuk membawa lebih banyak pengunjung ke dalam destinasi wisata tersebut. Sedangkan, menurut Pantouw dan Pangemanan (2014:50), citra tempat bisa menghipnotis wisatawan dalam tetapkan perjalanan, perilaku pada tempat tujuan maupun tingkat kepuasan dan ingatan menurut pengalaman.

Dapat disimpulkan bahwa citra tujuan wisata merupakan citra baik dari tujuan wisata, meliputi fasilitas sarana prasarana tempat wisata yang disediakan oleh pengelola wisata. Dimana secara langsung memenuhi kebutuhan wisatawan. 
Dari beberapa teori di atas, maka dapat disimpulkan bahwa destination image memiliki beberapa komponen yaitu: citra kognitif, citra afektif dan citra konatif. Menurut Wang et al., (2011:113), menyatakan bahwa terdapat 4 dimensi dalam destination image, yaitu:

1) Natural and cultural resources (sumber daya alam dan budaya): keanekaragaman sumber daya alam, menarik dari pemandangan dan atraksi budaya bertani;

2) Atmosphere (suasana): udara segar, peluang untuk pengalaman rekreasi dan lingkungan pariwisata bersih;

3) Leisure infrastructures (kenyamanan infrastuktur): fasilitas kesehatan wisata, tersedia minuman dan makanan, oleh-oleh lokal;

4) Social setting and environment (pengaturan sosial dan lingkungan): tempat untuk wisata keluarga, tempat untuk mengajar di luar ruangan dan tempat untuk bermain.

Berdasarkan beberapa pendapat para ahli tersebut maka dapat ditarik kesimpulan bahwa terdapat empat dimensi dalam destination image, yaitu sumberdaya alam dan budaya, suasana/lingkungan, infrastruktur dan aksesbilitas, liburan dan hiburan wisatawan.

\section{Pengalaman Berwisata Yang Tak Terlupakan}

Menurut Chandralal dan Valenzuela (2013:180), teori memorable tourism experiences berasal dari kekuatan pengaruh memori masa lalu pada pengambilan keputusan konsumen. Menurut Tung dan Ritchie (2011:1369), mendefinisikan pengalaman pariwisata sebagai evaluasi subyektif individu dan menjalani (yaitu, efektif, kognitif, dan perilaku) dari peristiwa yang berkaitan dengan kegiatan wisatawan yang dimulai sebelum (perencanaan dan persiapan), selama (di tujuan), dan setelah perjalanan (ingatan).

Dapat disimpulkan bahwa memorable tourism experiences merupakan pengalaman berwisata yang dialami oleh individu berupa memori masa lalu dari kegiatan pariwisata yang dimulai sebelum, selama dan setelah perjalanan wisata.

Menurut Zhang et al., (2018:2), memorable tourism experiences adalah pengalaman yang dibangun secara selektif dari pengalaman wisata dan dapat diingat dan diingat setelah perjalanan. memorable tourism experiences lebih penting karena hanya pengalaman yang diingat akan mempengaruhi pengambilan keputusan wisatawan di masa depan. Sedangkan, menurut Chen dan Rahman (2018:161), memorable tourism experiences terutama pariwisata budaya dapat menjadi indikator kualitas yang berharga bagi pengelola destinasi. Dari beberapa teori di atas, maka dapat disimpulkan bahwa memorable tourism experiences menjadi indikator penting dalam mempengaruhi pengambilan keputusan wisatawan dalam berkunjung ke suatu destinasi wisata sebagai pengalaman berwisata yang mudah diingat. Menurut Zhang et al., (2018:3) menyatakan bahwa memorable tourism experience terdapat 7 dimensi, yaitu:

1) Hedonism (hedonism) adalah bentuk gaya hidup dimana kenikmatan atau kebahagiaan pribadi menjadi tujuan dalam menjalani hidup;

2) Novelty (kebaruan) adalah merujuk pada sesuatu yang baru atau memberi pengalaman baru;

3) Local culture (budaya lokal) merupakan pengalaman terhadap budaya lokal;

4) Refreshment (penyegaran) adalah yaitu perasaan tenang, segar dan lepas yang dirasakan selama kunjungan wisata; 
5) Meaningfulness (makna/arti penting) adalah berpartisipasi pada suatu kegiatan periwisata diantaranya dalam meningkatkan perasaan suasana hati dan perasaan senang seseorang;

6) Involment (keterlibatan) merupakan keterlibatan seseorang dalam suatu perjalanan wisata;

7) Knowledge (pengetahuan) merupakan pengetahuan mengenai perjalanan tempat wisata yang dikunjungi.

Dapat ditarik kesimpulan bahwa terdapat tujuh dimensi dalam memorable tourism experiences, yaitu hedonis, kebaruan, budaya lokal, penyegaran, arti penting, keterlibatan dan pengetahuan.

\section{METODE PENELITIAN}

\section{Tempat dan Waktu Penelitian}

Penelitian dilaksanakan di Obyek Wisata Pemandian Air Panas Gunung Torong yang beralamat di Desa Sukamanah, Kecamatan Kaduhejo, Kabupaten Pandeglang. Penelitian dilaksanakan selama 6 (enam) bulan, yaitu dimulai dari bulan Januari 2020 sampai bulan Juni 2020. Waktu tersebut digunakan karena merupakan waktu yang tepat dan efektif untuk melakukan penelitian.

\section{Metode Penelitian}

Penelitian ini menggunakan metode penelitian pendekatan kuantitatif dimana statistika sebagai teknik analisis untuk menguji suatu teori. Penelitian ini mendapatkan sumber data melalui survei dengan kuesioner yang disebarkan pada responden. Peneliti menggunakan data primer yang diperoleh secara langsung oleh peneliti untuk sumber penelitian. Data diperoleh dari hasil kuesioner yang berasal dari sampel penelitian.

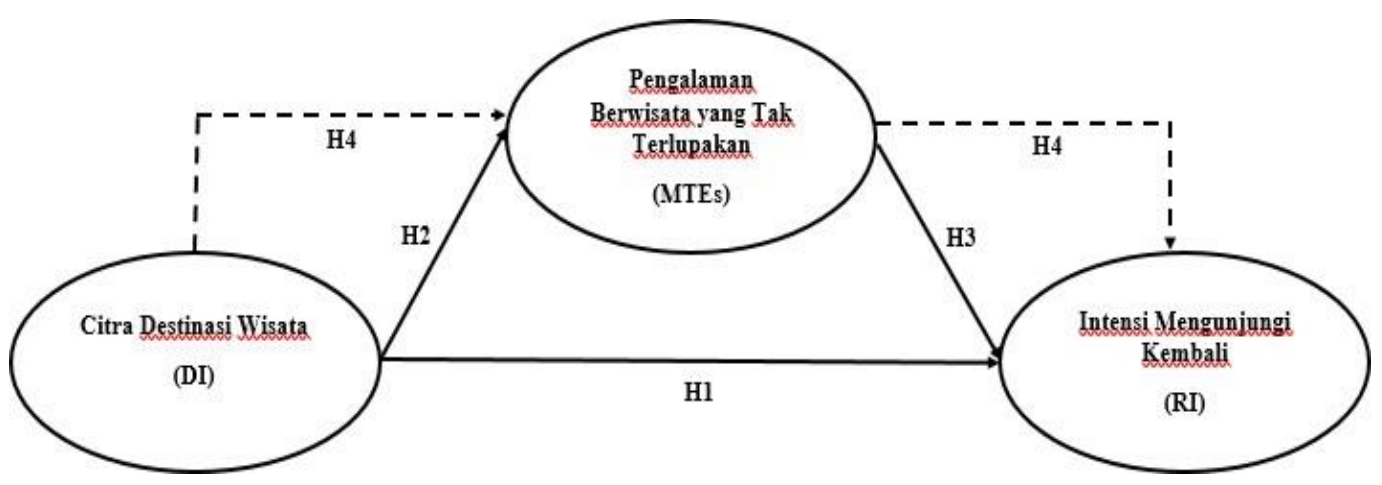

Gambar 3. Konstelasi Citra Destinasi Wisata dan Pengalaman Berwisata dengan Intensi Mengunjungi Kembali

\section{Jenis dan Sumber Data}

Data yang digunakan pada penelitian ini merupakan data kuantitatif. Adapun cara memperolehnya yaitu dengan menggunakan data primer. Data primer sendiri diperoleh dari hasil kuesioner yang merupakan data langsung dari sumber penelitian. Sumber data pada penelitian ini diperoleh dari hasil kuesioner yang sudah disebar kepada sampel penelitian. 


\section{Populasi dan Sampel}

Populasi pada penelitian ini adalah wisatawan Obyek Wisata Pemandian Air Panas Gunung Torong. Pengambilan sampel menggunakan metode purposive sampling, dengan kriteria wisatawan pernah dua kali mengunjungi Obyek Wisata Pemandian Air Panas Gunung Torong dalam waktu 3 (enam) bulan terakhir dengan jumlah sampel sebanyak 150 responden.

\section{Teknik Pengumpulan Data}

Dalam penelitian ini, teknik pengumpulan data menggunakan survei. Alasan peneliti memilih metode survei karena sesuai dengan tujuan yang ingin dicapai, yaitu untuk mengetahui hubungan antara variabel bebas dan variabel terikat. Dalam penelitian ini memiliki 3 (tiga) variabel, yaitu intensi mengunjungi kembali (RI), citra destinasi wisata (DI) dan pengalaman berwisata yang tak terlupakan (MTEs).

\section{Teknik Analisis Data}

Metode analisis digunakan untuk menginterpretasikan dan mengambil kesimpulan dari data yang sudah dikumpulkan. Peneliti menggunakan software SPSS Statistical Product and Service Solution versi 24 dipilih sebab dinilai lebih akurat. Uji yang digunakan dalam penelitian ini adalah: (1) Uji Prasyaratan Analisis yang meliputi Uji Normalitas dan Linearitas, (2) Mencari Persamaan Analisis Jalur (Path Analysis), dan (3) Uji Koefisien yang meliputi Uji Koefisien Korelasi dan Koefisien Determinasi.

\section{HASIL DAN PEMBAHASAN}

Hasil pengujian uji normalitas ini menggunakan One Sample Kolmogorov-Smirnov Test dengan tingkat signifikan $(\alpha) 5 \%$ atau 0,05 memiliki kriteria, yaitu jika nilai signifikansi atau Asymp. Sig (2-tailed) lebih besar dari 0,05 maka data berdistribusi normal. Sebaliknya, maka data berdistribusi tidak normal. Hasil uji normalitas dari data residual dengan pengujian One Sample Kolmogrov-Smirnov Test menggunakan SPSS versi 24. uji normalitas menggunakan pengujian One Sample Kolmogorov-Smirnov Test, didapatkan bahwa nilai Asymp Sig. (2-tailed) Kolmogorov-Smirnov sebesar 0,686 > 0,05 maka dapat disimpulkan bahwa data berdistribusi normal.

Hasil pengujian uji linearitas dengan melihat nilai signifikan pada Deviation from Linearity dari setiap variabel $>0,05$ atau $\mathrm{F}_{\text {hitung }}>\mathrm{F}_{\text {tabel }}$ sehingga dapat disimpulkan bahwa data yang digunakan dalam penelitian ini memiliki hubungan yang linear.

Tabel 4 Korelasi Citra Destinasi Wisata (DI), Pengalaman Berwisata (MTEs), dan Intensi Mengunjungi Kembali (RI)

\begin{tabular}{clrrr} 
& \multicolumn{1}{c}{ Correlations } & \\
\cline { 2 - 5 } Citra Destinasi Wisata (DI) & \multicolumn{2}{c}{$\begin{array}{c}\text { Pengalaman } \\
\text { Berwisata (MTEs) }\end{array}$} & $\begin{array}{c}\text { Intensi Mengunjungi } \\
\text { Kembali (RI) }\end{array}$ \\
\hline & $\begin{array}{l}\text { Pearson } \\
\text { Citra Destinasi Wisata (DI) }\end{array}$ & Correlation & $.924^{* *}$ & $.894^{* *}$ \\
\cline { 2 - 5 } & Sig. (2-tailed) & .000 & .000 \\
\cline { 2 - 5 } & $\mathrm{N}$ & 150 & 150 & 150 \\
\hline
\end{tabular}




\begin{tabular}{|c|c|c|c|c|}
\hline Pengalaman & $\begin{array}{c}\text { Pearson } \\
\text { Berwisata } \\
\text { Correlation }\end{array}$ & $.924^{* *}$ & 1 & $.930^{* *}$ \\
\hline \multirow[t]{2}{*}{ (MTEs) } & Sig. (2-tailed) & .000 & & .000 \\
\hline & $\mathrm{N}$ & 150 & 150 & 150 \\
\hline Intensi & $\begin{array}{cl} & \text { Pearson } \\
\text { Mengunjungi } & \text { Correlation } \\
\end{array}$ & $.894^{* *}$ & $.930^{* *}$ & 1 \\
\hline \multirow[t]{2}{*}{ Kembali (RI) } & Sig. (2-tailed) & .000 & .000 & \\
\hline & $\mathrm{N}$ & 150 & 150 & 150 \\
\hline
\end{tabular}

**. Correlation is significant at the 0.01 level (2-tailed).

Berdasarkan tabel di atas, nilai Pearson Correlation yang didapatkan antara citra destinasi wisata dengan intensi mengunjungi kembali adalah bernilai positif. Hasil korelasi diperoleh angka sebesar 0,894 dengan nilai probabilitas (sig) $=0,000(0,000<$ $0,05)$, artinya terdapat korelasi yang signifikan. Mengacu pada tabel interpretasi tingkat korelasi, maka korelasi antar variabel dikategorikan sangat kuat untuk tingkat korelasinya. Nilai Pearson Correlation yang didapatkan antara Pengalaman berwisata yang tak terlupakan dengan intensi mengunjungi kembali adalah bernilai positif. Hasil korelasi diperoleh angka sebesar 0,930 dengan nilai probabilitas (sig) $=0,000(0,000<$ $0,05)$, artinya terdapat korelasi yang signifikan. Mengacu pada tabel interpretasi tingkat korelasi, maka korelasi antar variabel dikategorikan sangat kuat untuk tingkat korelasinya.

Nilai Pearson Correlation yang didapatkan antara citra destinasi wisata dengan pengalaman berwisata yang tak terlupakan adalah bernilai positif. Hasil korelasi diperoleh angka sebesar 0,924 dengan nilai probabilitas $(\mathrm{sig})=0,000(0,000<0,05)$, artinya terdapat korelasi yang signifikan. Mengacu pada tabel interpretasi tingkat korelasi, maka korelasi antar variabel dikategorikan sangat kuat untuk tingkat korelasinya.

Tabel 5 Rangkuman Dekomposisi Koefisien Jalur

\begin{tabular}{lcccc}
\hline Pengaruh Variabel & \multicolumn{2}{l}{ Pengaruh Kausal } & Sisa \&1 \& \&2 & \multirow{2}{*}{ Total } \\
\cline { 2 - 5 } Individu & Tidak Langsung & & - & 0,894 \\
DI terhadap RI & 0,894 & - & - & 0,924 \\
DI terhadap MTEs & 0,924 & - & 0,383 & 1,236 \\
$\mathrm{R}^{2}$ DI terhadap & 0,853 & - & - & 0,859 \\
MTEs & - & $(0,924 \times 0,930)$ & - & 0,930 \\
DI terhadap RI & - & - & & 1,753 \\
melalui MTEs & 0,930 & & 0,355 & 1,229 \\
MTEs terhadap RI & $0,894+(0,924 \times 0,930)$ & & - \\
Pengaruh Total & 0,874 & &
\end{tabular}

Berdasarkan tabel di atas dapat terlihat bahwa terdapat pengaruh langsung dan tidak langsung dari masing-masing hubungan antar variabel. Sumbangan simultan dari variabel 
Citra Destinasi Wisata (DI) dan Pengalaman Berwisata (MTEs) terhadap Intensi Mengunjungi Kembali (RI) adalah sebesar 87,4\% atau variabel bebas Citra Destinasi Wisata (DI) dan Pengalaman Berwisata (MTEs) mampu menjelaskan sebesar 87,4\% variabel terikat Intensi Mengunjungi Kembali (RI). Sedangkan, sisanya sebesar 35,5\% dipengaruhi oleh faktor-faktor di luar penelitian ini.

\section{KESIMPULAN DAN SARAN}

Terdapat pengaruh positif dan signifikan citra destinasi wisata terhadap intensi mengunjungi kembali. Artinya persepsi wisatawan yang semakin tinggi akan citra destinasi wisata maka meningkatnya intensi mengunjungi kembali pada wisatawan. Terdapat pengaruh positif dan signifikan citra destinasi wisata terhadap pengalaman berwisata yang tak terlupakan. Artinya persepsi wisatawan yang semakin tinggi akan citra destinasi wisata maka berkesan positif pengalaman berwisata yang dirasakan oleh wisatawan. Terdapat pengaruh positif dan signifikan tuntutan pengalaman berwisata yang tak terlupakan terhadap intensi mengunjungi kembali. Artinya semakin berkesan pengalaman berwisata yang dirasakan oleh wisatawan maka akan meningkatkan intensi mengunjungi kembali wisatawan. Terdapat pengaruh positif dan signifikan citra destinasi wisata terhadap intensi mengunjungi kembali melalui pengalaman berwisata yang tak terlupakan. Artinya semakin tinggi citra destinasi wisata dan pengalaman berwisata yang tak terlupakan yang dimiliki oleh mahasiswa maka akan meningkatkan intensi mengunjungi kembali wisatawan.

Berdasarkan hasil penelitian yang diperoleh, maka beberapa saran di bawah ini dapat berguna dan bermanfaat di kemudian hari. Beberapa saran tersebut antara lain:

Indikator terendah pada variabel intensi mengunjungi kembali adalah mungkin menjadi tujuan liburan, sebesar 19,64\%. Rendahnya indikator tersebut karena wisatawan masih berpikir untuk merencakan tujuan liburan berikutnya, karena banyak tempat wisata lain yang menarik perhatian wisatawan untuk di kunjungi. Hal tersebut, harus didorong dengan strategi pemasaran yang tepat.

Pada variabel citra destinasi wisata indikator terendah adalah tempat untuk mengajar di luar ruangan sebesar 8,23\%. Rendahnya persentase skor indikator tersebut disebabkan karena dengan memiliki persepsi citra destinasi wisata maka sudah pasti wisatawan telah merasakan pengalaman rekreasi namun belum tentu wisatawan akan mengunjungi tempat wisata di masa yang akan datang karena tempat tersebut tidak cocok untuk tempat edukasi. Hal ini menunjukan bahwa harus ada peningkatan sarana dan prasarana fasilitas yang dilakukan pengelola wisata dalam menjalankan tempat wisata.

Selanjutnya, pada variabel pengalaman berwisata indikator terendah adalah mengalami budaya lokal sebesar 4,06\%. Rendahnya persentase skor indikator tersebut disebabkan karena wisatawan saat ingin mengunjungi kembali tempat wisata merasa kecewa karena meskipun tempat wisata tersebut berada di alam terbuka tetapi tidak ada kegiatan aktivitas dengan penduduk lokal yang dimana merupakan kegiatan yang harus diikuti saat berwisata di pedesaan.

Pada penelitian ini, peneliti tidak menguji pangaruh variabel promosi terhadap intensi mengunjungi kembali pada tempat wisata. Bagi peneliti yang ingin meneliti mengenai intensi mengunjungi kembali pada sektor pariwisata, peneliti 
merekomendasikan untuk menguji pengaruh promosi terhadap intensi mengunjungi kembali. Agar lebih bermanfaat dan menambah ilmu di bidang sektor pariwisata.

\section{DAFTAR PUSTAKA}

Chandralal, L., \& Valenzuela, F.-R. (2013). Exploring memorable tourism experiences: Antecedents and behavioural outcomes. Journal of Economics, Business and Management, 1(2), 177-181.

Chen, H., \& Rahman, I. (2018). Cultural Tourism: An Analysis of Engagement, Cultural Contact, Memorable Tourism Experience and Destiantion Loyalty Tourism Management Perspectives, 26, 153 - 163. doi:10.1016

Coban, S. (2012). The effects of the Image of Destination on Tourist Satisfaction and Loyalty: The Case of Cappadocia. European Journal of Social Sciences, 29(2), 222-232.

Hsu, C. H., Cai, L. A., \& Li, M. (2010). Expectation, motivation, and attitude: A tourist behavioral model. Journal of travel research, 49(3), 282-296.

Jeon, H. (2013). The Effect of Experiential Marketing on Customer Satisfaction and Revisit Intention of Beauty Salon Franchise Stores. Journal of Fashion Business, 17(3), 109-121.

Kemenpar. (2020). Data Kunjungan Wisatawan Mancanegara Bulanan Tahun 2019. Retrieved Februari 10, 2020 from www.kemenpar.go.id website: https://www.kemenpar.go.id/post/data-kunjungan-wisatawanmancanegara- bulanan-tahun-2019

Kemenparekraf. (2019). Siaran Pers : Pariwisata Diproyeksikan Jadi Penyumbang Devisa Terbesar Lima Tahun ke Depan. Retrieved Februari 10, 2020, from https://www.kemenparekraf.go.id/post/siaran-pers-pariwisatadiproyeksikan-jadi- penyumbang-devisa-terbesar-lima-tahun-ke-depan website:

Lin, \& Chung-Hsien. (2014). Effects of Cuisine Experience, Psychological Well-Being, and Self-Health Perception on The Revisit Intention of Hot Springs Tourists. Journal of Hospitality \& Tourism Research, 38(2), 243-265. doi:doi:10.1177/1096348012451460

Pantouw, P., \& Pangemanan, S. S. (2014). The Effect Of Destination Image And Tourist Satisfaction On Intention To Revisit In Lembeh Hill Resort. Jurnal EMBA: Jurnal Riset Ekonomi, Manajemen, Bisnis dan Akuntansi, 2(3).

Sindonews. (2017). Kontribusi Pertumbuhan Pariwisata di Sektor Ekonomi Terbesar dan Tercepat. Retrieved Februari 10, 2020 from https://ekbis.sindonews.com website: https://ekbis.sindonews.com/read/1231216/34/kontribusi-pertumbuhanpariwisata- di-sektor-ekonomi-terbesar-dan-tercepat-1502940648

Stylos, N., Vassiliadis, C. A., Bellou, V., \& Andronikidis, A. (2016). Destination images, holistic images and personal normative beliefs: Predictors of intention to revisit a destination. Tourism Management, 53, 40-60. 
Tung, V. W. S., \& Ritchie, J. B. (2011). Exploring the essence of memorable tourism experiences. Annals of tourism research, 38(4), 1367-1386.

Wang, Y.-H., Wang, Y.-H., Chiu, J.-H., Liou, J.-Y., \& Yu-ShiangYang. (2015). Recreation Benefit, Recreation Experience, Satisfaction, and Revisit Intention Evidence from Mo Zai Dun Story Island. Journal of Business \& Economic Policy, 2(2), 53-61.

Wibowo, S. F., Sazali, A., \& Rivai, A. K. (2016). The Influence of Destination Image and Tourist Satisfaction Toward Revisit Intention of Setu Babakan Betawi Cultural Village. Jurnal Riset Manajemen Sains Indonesia (JRMSI), 7(1), 136-156.

Wikipedia. (2019). Kabupaten Pandeglang. Retrieved Februari 10, 2020, from Wikipedia Ensiklopedia Bebas website: https://id.wikipedia.org/wiki/Kabupaten_Pandeglang Yoeti, O. A. (2008). Ekonomi Pariwisata. Jakarta: Kompas.

Zhang, H., Wu, Y., \& Buhalis, D. (2018). A Model of Perceived Image, Memorable Tourism Experiences and Revisit Intention. Journal of Destination Marketing \& Management, 8, 326-336.

Zhang, H., Xu, F., Leung, H. H., \& Cai, L. A. (2016). The influence of destination-country image on prospective tourists' visit intention: Testing three competing models. Asia Pacific Journal of Tourism Research, 21(7), 811-835. 